\title{
ANALIZA RADA VENTILA SIGURNOSTI U USLOVIMA PREGREVANJA U ZATVORENIM SISTEMIMA CENTRALNOG GREJANJA ${ }^{1}$
}

\section{ANALYSIS OF THE SAFETY VALVE OPERATION UNDER OVERHEATING CONDITIONS IN CLOSED HEATING SYSTEMS}

\author{
Željko VLAOVIĆ , (Mentor Doc. dr Borivoj Stepanov) \\ Faculty of Technical Sciences, University at Novi Sad, Novi Sad, Serbia
}

https://doi.org/10.24094/kghk.018.49.1.287

\begin{abstract}
Cilj rada je analiza sigurnosnih ventila u uslovima pregrevanja, za koje nisu projektovani. Njihov radni temperaturski opseg je do $110^{\circ} \mathrm{C}$. Pri pregrevanju u sistemu temperatura može porasti preko $110^{\circ} \mathrm{C}$ i sistem može ući u oblast ključanja. U tim uslovima, prilikom ekspanzije do atmosferskog pritiska dolazi do isparavanja u ventilu, koje dovodi do smanjenja masenog fluksa, što je izračunato raspoloživim metodama, koje su detaljno opisane.
\end{abstract}

Ključne reči:pregrevanje u sistemima centralnog grejanja, isparavanje u ventilu sigurnosti, povećanje pritiska

The aim of this study is the analysis and evaluation of safety valves in conditions of overheating, for which they are not designed. Their working temperature range is up to $110^{\circ} \mathrm{C}$ and the system may enter the boiling region. Under these conditions, during expansion to atmospheric pressure, flashing may occur in a valve, which leads to decrease of the mass flux. The mass flux is calculated with the available methods, which are described in details.

Key words: overheating in central heating system, flashing in safety valve, pressure increase.

\section{Introduction}

Standard SRPS EN 303-5:2016 (Heating boilers for solid fuels, manually and automatically stoked, nominal heat output of up to $500 \mathrm{~kW}$ - Terminology, requirements, testing and marking) specifies when solid fuel boilers can be installed in closed heating systems, only when heat production can be quickly regulated. This is not possible in the standard construction of a boiler that dates back to the 70 s of the last century. Pellet boilers can be quickly regulated. In Serbia engineers do not follow this procedure. Safety valves cannot be designed for such conditions because in case of overheating they will try to maintain pressure within the allowed limits, but are not able to take away excess heat, which does not stop the overheating. Overheating can be defined as the difference between the produced heat in the boiler and the heat delivered to the user via the radiator. The increase of temperature in the boiler is the problem that can occur. That increase of temperature can indicate that the boilers controller damper for inlet of air failed. In boilers that are using solid fuel, the air supply is regulated by a damper control, by closing the air damper. In case of an increase in temperature, the temperature controller dampens the air supply to reduce heat production. Even if the regulator closes the clapper, a certain portion of the air will be infiltrated. Another reason for increasing the temperature may be the failure of the circulation pump. A certain portion of natural circulation will still exist based on the difference in density, but the bigger part of the produced heat will be kept inside the boiler, because it cannot be forwarded to the consumer. Also, there is a possibility that the air can be found in the system, and that air can form an air cap. The air cap represents the barrier to circulation. The pump is not able to maintain the circulation and the heat production system (boiler) is completely separated from the heat recovery system (radiators). The maximum overheating is determined by the maximum capacity of the boiler itself. Due to temperature increase, pressure also increases. At temperatures above $100^{\circ} \mathrm{C}$, a vapor explosion can happen. Each boiler is dimensioned to withstand a certain pressure, and if this pressure increases over the maximum allowed pressure, a catastrophe is going to happen. The safety valve is the last protection. It maintains the pressure in the boiler, but it does not have the ability to maintain the temperature, or the possibility to remove the heat.

The safety valves most commonly installed in closed central heating systems are from Italian manufacturer "Calleffi". In technical documentation of the safety valves, prescribed by the manufacturer, the operation temperature range is up to $110^{\circ} \mathrm{C}$.

Assuming the change isobaric (that the safety valve manages to maintain pressure at the given level), an analysis of the safety valve capacity, based on the calculated mass flux, was performed. Some of the methods for determining the mass flux and the maximum mass flow have been presented in relation to different initial temperatures and mass fraction. Also, a comparison of the obtained results is presented [1].

\section{Two-phase flow through valve}

There are different methods for calculating mass flux. A very important parameter is the character of the flow through the valve. It can be single-phase (water or steam) or two-phase (mixture). Many models that are used for

\footnotetext{
${ }^{1}$ This paper was presented at the National Students Competition 2018 organized by the Serbian HVAC\&R Society.

${ }^{2}$ Corresponding author's e-mail: vlaovicz@uns.ac.rs
} 
predicting two-phase flow through an ideal nozzle are available in the literature. The two-phase flow calculation methods currently considered as the most suitable for the dimensioning of safety valves are based on a homogeneous equilibrium or homogeneous imbalance model.

The homogeneous equilibrium model implies that the fluid flowing through the valve is a two-phase (gas-liquid) mixture, that it is "well" mixed that it can be presented as a single-phase fluid with properties that are a combination of both phases, also these two phases are in mechanical and thermodynamic equilibrium. These assumptions are indispensable, but not sufficient for calculation. Calculation of density of the fluid in terms of pressure and saturation is also needed [2].

\subsection{Thermodynamic equilibrium}

The usual assumption is that the gas or vapor phase is in the thermodynamic equilibrium with the liquid phase, which means that the properties of the mixture are a function of only the temperature, the pressure and their fraction. In other words, when the fluid pressure drops to the saturation pressure, evaporation will occur immediately if the system is in equilibrium. However, evaporation is actually a process that requires a certain amount of time (e.g. several milliseconds) to fully develop. During this time, the liquid can flow a few centimeters through the valve nozzle. Under these conditions, the amount of steam produced, is much smaller than it would have been under equilibrium conditions, and the density of the mixture and the mass flux are proportionately higher. Experimental data showed that in a large number of individual single-component systems, the length of the nozzle of minimum $10 \mathrm{~cm}$ is sufficient to establish an equilibrium, which implies that the flow in nozzles shorter than $10 \mathrm{~cm}$ can be considered as a non-equilibrium flow [3].

\subsubsection{Flashing in safety valves}

For an easier explanation of the flashing in safety valves, the term vapor pressure must first be defined. Vapor pressure or saturated vapor pressure is the pressure above the liquid level. At this pressure, a balance is established between the evaporating molecules and those that condense. When the local pressure drops below the vapor pressure, the liquid will start to evaporate intensively [4].

\section{Safety relief valve sizing}

The required cross-section area of the nozzle is determined on the basis of the mass flow and mass flux:

$$
A=\frac{\dot{m}}{K_{D} \cdot G_{0}} .
$$

The value of the mass flux is calculated using the equation for an isentropic nozzle, by the adopted model and multiplied by the discharge coefficient, in order to obtain a real mass flux. As shown in Figure 1, there are similarities and differences between the ideal and the actual nozzle [5].

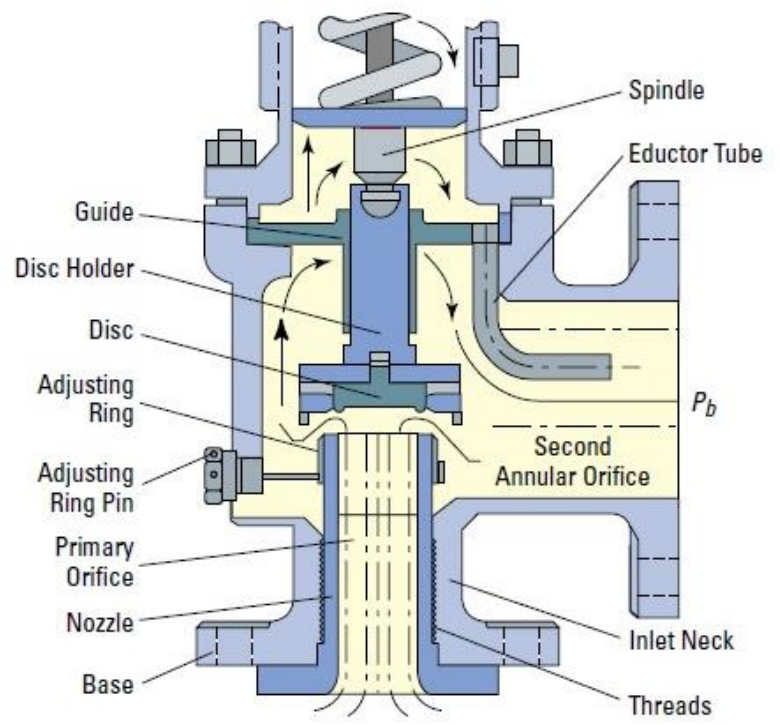

(a) Actual safety-relief valve

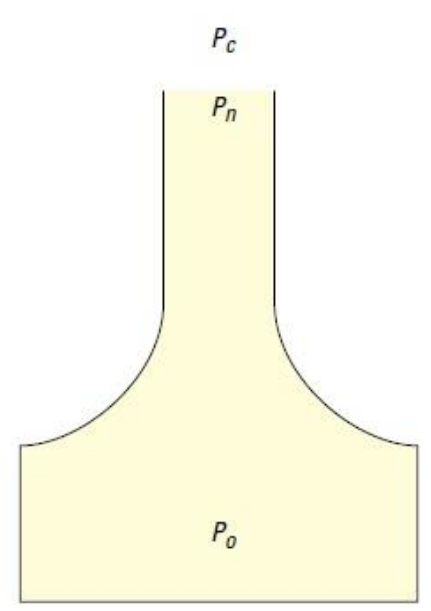

(b) Ideal nozzle

Figure 1: An actual safety relief valve (left) and an ideal nozzle (right) 


\section{The HDI method (the Homogeneous Direct Integration method)}

When calculating mass flux by using this method, it is necessary to be familiar with the thermodynamic states. Here, the density represents the dependence of pressure change, that is calculated by the constant entropy, in the range from Po to Pa. Mass flux is calculated using the formula [2]:

$$
G_{0}=\rho_{n} \cdot\left(-4 \sum_{P o}^{P n} \frac{P_{i+1}-P_{i}}{\rho_{i+1}+\rho_{i}}\right)^{\left(\frac{1}{2}\right)}
$$

The lower the pressure increments are, the results are more accurate. In order to determine the pressure at which flashing occurs, we repeat the calculation process by reducing the pressure for the adopted increment, until the maximum mass flux is reached, starting from $P_{o}=P_{n}$. If the maximum mass flux is achieved at the exit of the valve $\left(P_{n}=P_{a}\right)$, where $\mathrm{Pa}$ is the pressure at the exit of the safety valve, atmospheric, there will be no flashing in the valve and the flow will not be chocked. This method has wide application and is applicable to all types of fluids, under any conditions. The method can also be extended for non-equilibrium flows, where the nozzle lengths are shorter than $10 \mathrm{~cm}$. The effect of a nonequilibrium flow is that the flashing will not occur immediately when the pressure drops below the saturation pressure, that is, when the pressure reaches the saturation pressure, the flashing will not fully develop because the mass fraction is less than the one that would have it for an equilibrium flow. Since the density for equilibrium two-phase flow is directly dependent on the mass fraction, it can be calculated using the formula:

$$
\frac{1}{\rho}=\frac{x}{\rho_{G}}+\frac{(1-x)}{\rho_{L}}
$$

For non-equilibrium conditions, where the nozzle length is shorter than $10 \mathrm{~cm}$, we must assume that the mass fraction reaches the equilibrium state $x_{e}$ as the length of the nozzle approaches the length of $10 \mathrm{~cm}$. For nozzles that are less than $10 \mathrm{~cm}$, the mass fraction in the nozzle is calculated as:

$$
x=x_{0}+\left(x_{e}-x_{0}\right) \cdot \frac{L}{10} .
$$

As the pressure in front of the nozzle $\left(P_{n}\right)$ decreases, the mass flux $\left(G_{0}\right)$ will grow. If it reaches its maximum before the pressure in the nozzle drops to the atmospheric, the mass flow of congestion will occur. For initial conditions of 3.5 bar of absolute pressure, temperature from $110^{\circ} \mathrm{C}$, mass fluxes are calculated. It should be kept in mind that the value of the maximum mass flux is calculated by using the formula:

$$
G_{n}=\frac{G_{0} \cdot K_{D}}{0,9}
$$

Where the value of 0.9 is the reccomended safety factor [3].

\section{The Omega method}

This method is described in the API 520-1 standard, and it can be used when sizing the safety valves for two-phase flows. The method uses the omega parameter to determine the state:

$$
\omega=\frac{x_{0} \cdot v_{G 0}}{v_{0}}+\frac{C_{f 0} \cdot T_{0} \cdot P_{0}}{v_{0}}\left(\frac{v_{f g o}}{v_{o}}\right)^{2} .
$$

In the case where the fluid is all in liquid phase at the beginning, the amount of steam is equal to zero. Omega parameter is calculated from formula (6). Based on the omega parameter and the ratio of critical pressures, we find that flashing occurs during flow through the valve. As we can see in Figure 2.

If the condition is satisfied that the saturation pressure is greater than the pressure at the exit of the valve, then the mass flux is calculated according to the formula [5]:

$$
\frac{G_{c}}{\sqrt{\frac{P_{0}}{v_{0}}}}=\frac{\eta_{c}}{\sqrt{\omega}} .
$$




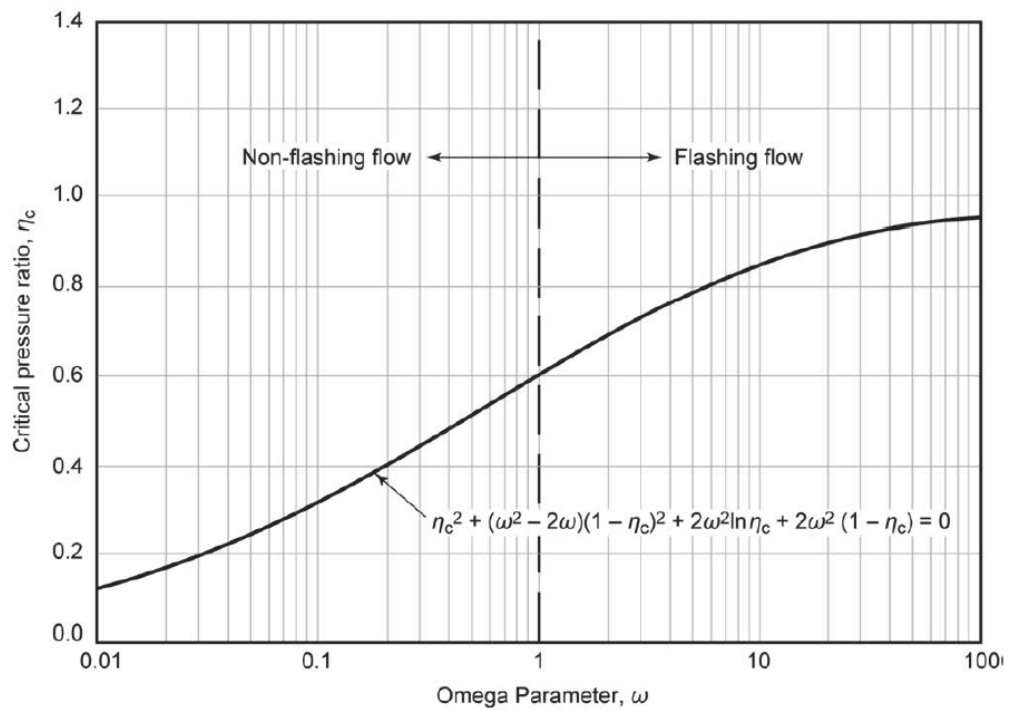

Figure 2: Ratio between critical pressure and omega parameter [6]

\subsection{Sizing for two-phase flashing or non-flashing flow through safety valve}

In the case when the fluid at the entrance is a subcooled liquid, it is necessary to check the conditions for the liquids with low or high subcooling. The formula for calculating the omega parameter is the same without the first member, since the quality of mass fraction is zero. For high subcooling case, mass fluxes are calculated according to the formula [7]:

$$
G_{c}=\sqrt{2 \cdot \rho_{f o}\left(P_{0}-P_{s}\right)} .
$$

\subsection{Sizing for subcooled liquid at the inlet of safety valve}

The presented method can be used for sizing safety valves for subcooled (including saturated) liquid at inlet. There must be no condensing vapor or non-condensing gas at the entrance. Depending on the flow regime, the liquid will evaporate before or after the nozzle. The formulas used can be applied to all liquids. The formula for calculating the omega parameter is:

$$
\omega_{s}=9 \cdot\left(\frac{\rho_{l 0}}{\rho_{9}}-1\right)
$$
[6]:

Based on the flow and fluid flow regime, according to API 520-1 standard, for the highly-tempered flow regime

$$
G=1,414 \sqrt{\rho_{l o}\left(P_{0}-P\right)}
$$

\section{Results}

Based on obtained results from Table 1, we can notice that the highest value of the mass flux is reached at a pressure of $1.45 \mathrm{bar}\left(16893 \mathrm{~kg} /\left(\mathrm{s} \cdot \mathrm{m}^{2}\right)\right)$, which implies that flow will be chocked in the safety valve at that pressure.

Table 2. Results obtained by numerical integration for equilibrium flow regime

\begin{tabular}{|c|c|c|c|c||}
\hline$P_{n}[\mathrm{bar}]$ & $\rho_{n}\left[\mathrm{~kg} / \mathrm{m}^{3}\right]$ & $\Delta P / \rho$ & $\sum \Delta P / \rho$ & $G_{\mathrm{N}}\left[\mathrm{kg} / \mathrm{s} \cdot \mathrm{m}^{2}\right]$ \\
\hline 3.5 & 951.05 & 0 & 0 & 0 \\
\hline 3.45 & 951.05 & -5.26 & -5.26 & 2683.46 \\
\hline 2.8 & 951.02 & -5.26 & -73.6 & 9871.9 \\
\hline 1.45 & 950.9 & -5.26 & -215.5 & 16893.16 \\
\hline 1.40 & 662.84 & -13.34 & -228.91 & 6859.4 \\
\hline
\end{tabular}

Depending on the state of the initial fluid, the mass flux will vary. The influence of the temperature in the subcooled area on the mass flow through the valve is shown in Table 1, and the influence of the mass fraction on the mass flux through the valve is shown in Tables 3,4 and 5. We can conclude that the maximum flux decreases with increasing both 
the temperature and the mass fraction. Table 2 shows the results of the maximum mass flux for different initial temperatures.

Table 2. Results obtained by numerical integration for different starting temperature in the system

\begin{tabular}{|l|c|c|c|c|c|c||}
\hline \hline$t\left[{ }^{\circ} \mathrm{C}\right]$ & 99 & 110 & 114.5 & 119 & 124 & 137 \\
\hline$G_{N}\left[\mathrm{~kg} / \mathrm{s} \cdot \mathrm{m}^{2}\right]$ & 17575 & 16893 & 15801 & 14635 & 13117 & 4516 \\
\hline
\end{tabular}

Table 3. Results obtained by numerical integration for different starting mass fraction in the system

\begin{tabular}{|l|l|l|l|l|l|l||}
\hline \hline$x_{e}[-]$ & 0.001 & 0.002 & 0.003 & 0.004 & 0.005 & 0.006 \\
\hline$G_{N}\left[\mathrm{~kg} / \mathrm{s} \cdot \mathrm{m}^{2}\right]$ & 2229 & 2220 & 2183 & 2146 & 2118 & 2098 \\
\hline
\end{tabular}

Table 4. Results obtained by numerical integration for different starting mass fraction in the system

\begin{tabular}{|l|l|l|l|l|l|l|l||}
\hline \hline$x_{e}[-]$ & 0.01 & 0.02 & 0.03 & 0.04 & 0.05 & 0.06 & 0.07 \\
\hline$G_{N}\left[\mathrm{~kg} / \mathrm{s} \cdot \mathrm{m}^{2}\right]$ & 2229 & 2220 & 2183 & 2146 & 2118 & 2098 & 1314 \\
\hline
\end{tabular}

Table 5. Results obtained by numerical integration for different starting mass fraction in the system

\begin{tabular}{|l|c|c|c|c|c|c|c|c||}
\hline \hline $\mathrm{X}_{e}[-]$ & 0.1 & 0.2 & 0.3 & 0.4 & 0.5 & 0.6 & 0.7 & 0.8 \\
\hline$G_{N}\left[\mathrm{~kg} / \mathrm{s} \cdot \mathrm{m}^{2}\right]$ & 1169 & 905 & 677 & 677 & 613 & 564 & 526 & 494 \\
\hline
\end{tabular}

With the increase in the initial temperature in the system, the maximum mass flux decreases, which can be seen in Figure 3, because the liquid at the expansion reaches the conditions for flashing. At the same time, the valve capacity is reduced up to 3.9 times compared to the reference value measured at $99{ }^{\circ} \mathrm{C}$.

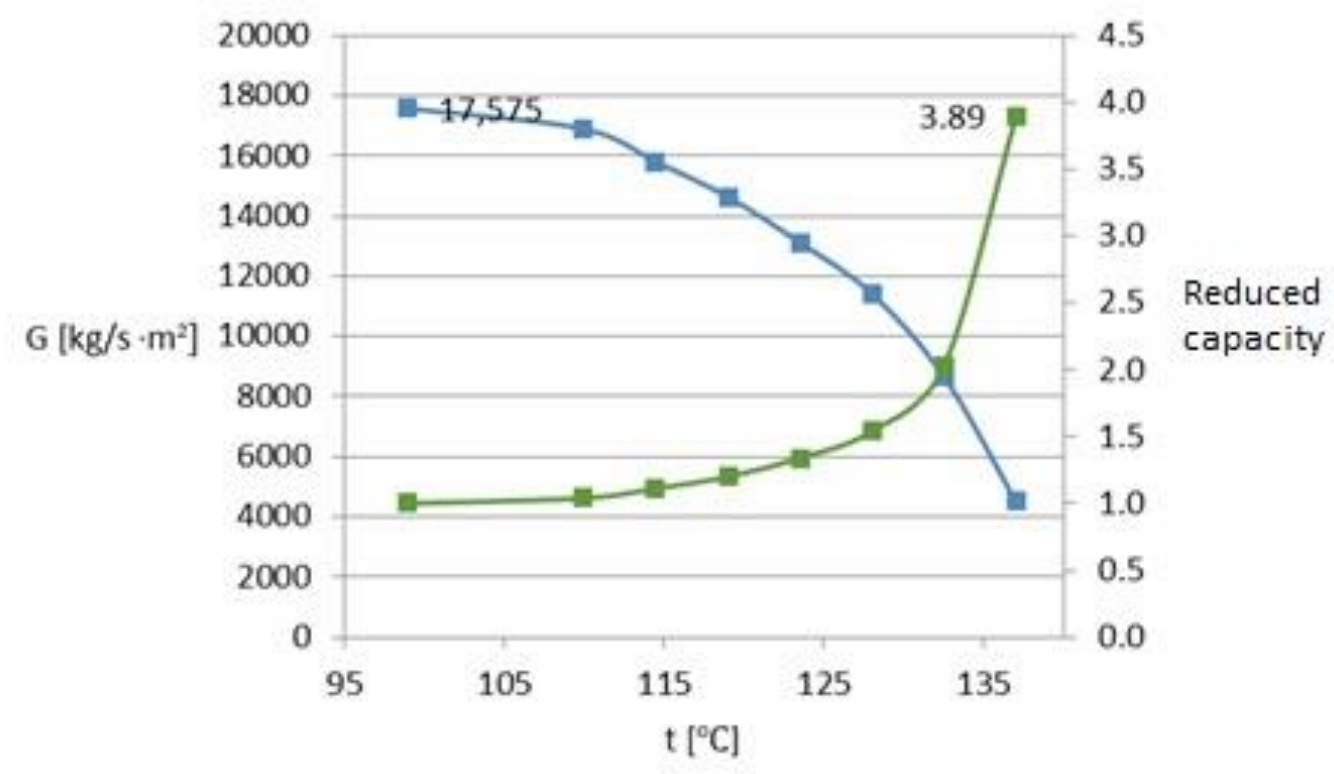

Figure 3: The maximum mass flux dependency diagram of increasing the initial temperature in the system and reducing the capacity of the valve relative to the reference value measured at $99^{\circ} \mathrm{C}$.

In analogy, Figure 4 shows the results of the maximum mass flux in relation to the different initial quality of mass fraction. We conclude that in the saturated region the capacity of the valve drastically decreases. 


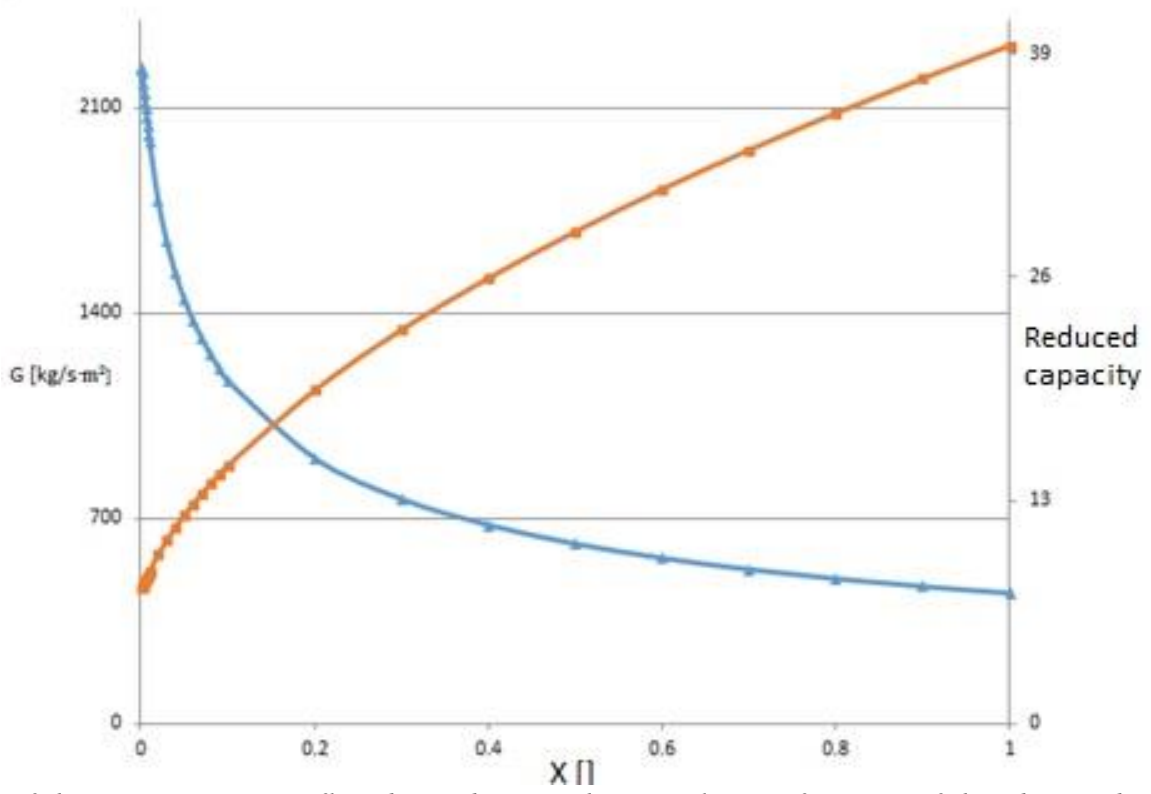

Figure 4: Values of the maximum mass flux depending on the initial mass fraction of the obtained and the reduction of the valve capacity relative to the reference value measured at $99^{\circ} \mathrm{C}$

\section{Conclusions}

An analysis of the operation of the safety valve in the closed central heating system during overheating was performed. We conclude that in the case of failure of control equipment or circulation stop, the safety valve is not able to regulate the increase in temperature in the closed system. The safety valve cannot take out the heat from the system, it only regulates the pressure. In the event of an increase in temperature above $100{ }^{\circ} \mathrm{C}$, there is a risk of a steam explosion. In such circumstances, the safety valve does not have a sufficient capacity to adequately react. Based on the calculation of the mass flux, depending on the initial temperature and saturation level, we can conclude that evaporation in the safety valve will occur, which implies that the flow in the valve will be chocked. The value of the mass flux depends directly on the initial conditions, above all the temperature and the pressure at which the safety valve opens. With an increase in the initial temperature in the system, the maximum value of the mass flux decreases, which negatively influences the flow in the valve itself. Evaporation occurs when the pressure in the nozzle drops below the vapor pressure, while flowing through the narrowing of the nozzle ("the vein contract"). In essence, evaporation in the safety valve limits the capacity of the valve, and it is not able to discharge the required amount of liquid. As the mass fraction increases, the mass flux decreases, and the valve capacity decreases proportionally. At the upper limit, the valve's capacity drops 38 times. At the lower limit, the valve's capacity drops 7 times. Reaching the state of the lower limit is more realistic in practice, which implies that a valve initially designed for boilers up to $72 \mathrm{~kW}$ can withstand the power of approximately $10 \mathrm{~kW}$. If we assume that the average boiler is $30 \mathrm{~kW}$, the result can be a serious threat to safety.

\section{References}

[1] *** SRPS EN 303-5:2016 - Kotlovi za grejanje na čvrsta goriva, ručno i automatski loženi, nazivne toplotne snage do $500 \mathrm{~kW}$

[2] Darby, R., Meiller, P. R., \& Stockton, J. R. (2001). Select the Best Model, (May).

[3] Darby, R., C. (2005). Size Safety-Relief Valves for Any Conditions, Published in Chemical Engineering, 112 , (9), 42-50.

[4] Bolle, L., Downar-Zapolski, P., Franco, J., \& Seynhaeve, J. M. (1996). Experimental and theoretical analysis of flashing water flow through a safety value. Journal of Hazardous Materials, 46(2-3), 105-116.

[5] Darby R., \& . Raj P.C. (2004). Chemical engineering fluid mechanics, third edition, chapter 11, $291-301$.

[6] *** American Petroleum Institute. (2008). Sizing, Selection and Installation of Pressure Relieving Devices in Refineries, Part I - Sizing and Selection. API Standard 520, (December 2008).

[7] Lees, F. P. (1996). Loss Prevention in the Process Industries: Hazard Identification, Assessment and Control, 1, 3776. 